\title{
Programas de cidadania fiscal: análise do estado da arte em programas de cidadania
}

\section{Fiscal citizenship programs: state of art analysis on fiscal citizenship programs}

\author{
James Vanin de Andrade \\ Universidade Tecnológica Federal do Paraná - UTFPR - Curitiba - Brasil \\ jamesvanin@gmail.com \\ Rosângela de Fátima Stankowitz \\ Universidade Tecnológica Federal do Paraná - UTFPR - Curitiba - Brasil \\ rosangelas@utfpr.edu.br \\ Dario Eduardo Amaral Dergint \\ Universidade Tecnológica Federal do Paraná - UTFPR - Curitiba - Brasil \\ dergint@utfpr.edu.br \\ Vivian Amaro Czelusniak \\ Centro Universitário Autônomo do Brasil - UniBrasil - Curitiba - Brasil \\ vivian.amaro@gmail.com
}

\section{Resumo}

Diversos programas de cidadania têm sido implantados pelos governos estaduais e municipais do Brasil. O objetivo deste artigo é fazer uma análise dos conteúdos abordados nas pesquisas sobre os programas de cidadania em âmbito nacional. Para isso, o embasamento teórico adotado nesta pesquisa é inerente aos conceitos adotados nestes programas. Assim, iniciou-se pela análise de comportamento dos contribuintes e cidadãos em face às ações governamentais de estímulo ou coerção. Para montar o quadro teórico, partiu-se dos principais pesquisadores nacionais e seus referenciais teóricos buscando-os no Google Academics e na plataforma Scopus. O conjunto de autores pesquisados realiza análise de variáveis comportamentais, como o aumento de compliance (adequação às regras) em face do risco de ser flagrado e a necessidade individual de aderência à norma social de conduta. Outros autores focam o estudo em análises quantitativas, nas quais se avaliam os resultados de arrecadação de impostos dos programas de cidadania com um todo, sem segmentar os impactos dos programas em diferentes setores econômicos; o que pode representar uma importante possibilidade de pesquisa para nortear outros programas em Estados ou Municípios que ainda não o implantaram.

Palavras-chave: Aumento de Arrecadação de Impostos, Evasão Fiscal, Programa de Incentivo fiscal, Cidadania Fiscal, Programa Fiscal.

\section{Abstract}

Various Citizenship programs have been established by both city and state governments 
in Brazil. The purpose of this article is to analyze the contents of researches on that subject in Brazil. For that purpose, the theoretical basis of this research is the one used in citizenship programs. Therefore, it has been started by the analysis of both citizens and tax payers behavior in face of government stimulus or deterence actions. In order to assemble a theoretical scenario, references quoted by main national researchers were searched on Google Academics and Scopus platform. Behavioral variables, such as the increase of compliance in face of getting caught by the government in an illegal act or the need of adherence to social behavior rules were observed. In the sequence, there has been a checking on quantitative researches and it was noticed that a big variety of aspects is taken into consideration among these researches. As a conclusion, it is pointed out that researches evaluate program's results as a whole, without splitting them into the distinct economical categories, which represents an important research possibility for future researches that may direct other citizenship programs in states that are yet to implement them.

Keywords: Increase on tax collection, Fiscal Evasion, Fiscal Citizenship Program, Fiscal Citizenship, Fiscal Program.

\section{Introdução}

Para recolher os tributos devidos pelos contribuintes, os governos precisam que as transações comerciais estajam documentadas e sejam declaradas. Programas de Cidadania buscam criar diversos estímulos para que os cidadãos peçam nota fiscal e, com isto, reduzam a evasão fiscal. Tendo em vista a proliferação destes programas, é de se supor que novos programas serão criados pelos governos. Obter informação sobre quais aspectos influenciam os resultados destes programas, e como as pesquisas atuais os endereçam, se revela um importante problema a ser pesquisado.

O aumento no número destes programas cria uma demanda por pesquisas que incrementem e norteiem estes projetos com o objetivo de aprimorá-los. Uma das maneiras mais usuais de avaliação destes programas é a quantificação de seus resultados em aspectos regionais, setoriais, temporais, etc. O princípio norteador de um programa de cidadania é a participação do cidadão solicitando notas fiscais para a geração de maior receita de impostos e aumento da consciência de cidadania do indivíduo. Vários estudos, como Naritomi (2015), Mattos, Rocha e Toporcov (2013) e Paschoal (2012) analisam mudanças do comportamento dos cidadãos enquanto atores ativos no combate à sonegação, e do comportamento dos comerciantes quando estimulados a dar transparência a seus atos comerciais. Logo, se torna relevante a verificação das metodologias quantitativas utilizadas para estas análises.

O ponto de partida do artigo é a identificação de estudos, em âmbito nacional, que tenham programas de cidadania em seu escopo.

\section{Referencial Teórico}

Entre os propósitos de um programa de cidadania há o incremento da arrecadação de impostos por meio da participação dos cidadãos e o aumento da consciência do papel de cidadania do indivíduo. Em um estudo realizado sobre um programa desta natureza, no Estado de São Paulo, Naritomi (2015, p. 30) conclui que:

[...] o programa aumentou o faturamento declarado em pelo menos $22 \%$ em quatro anos. Eu examino a heterogeneidade entre estabelecimentos e a resposta dos consumidores a prêmios para colocar luz no mecanismo pelo qual informações de terceiros podem incrementar o cumprimento da lei a despeito da oportunidade de conluio para sonegação de impostos. Descobri que o efeito é mais forte para 
setores com maior volume de transações, consistentemente com o aumento da probabilidade de auditoria devido ao perigo de reclamações por parte dos clientes. Ainda ofereço evidências diretas do efeito repressivo de consumidores realizando reclamações: Empresas relatam 14\% mais recibos e 6\% mais faturamento depois de receberem a primeira reclamação (NARITOMI, 2015, p. 30)

Em outros estudos sobre o nota paulista, a nota gaúcha e nota legal em Pernambuco, Santos (2015), Carvalho et al. (2016) e Magalhães e Siqueira (2007) avaliam os impactos obtidos por meio da participação popular. O mecanismo é muito simples: o governo estimula o cidadão a pedir a nota fiscal no momento da compra oferecendo benefícios como devolução de parte do imposto daquela venda, ou por meio de bilhetes para participar de sorteios de prêmios significativos em dinheiro. Assim, mais notas são pedidas e mais impostos são pagos. Segundo Naritomi (2015), mesmo pequenos prêmios geram um incremento significante e constante no número de notas fiscais de diferentes estabelecimentos comerciais nos quais as notas são pedidas.

O conjunto de fatores que levam à obtenção destes resultados pode ser encontrado em diferentes perspectivas. Na obra Crime and Punishment, Becker (1968) discorre sobre as motivações de um indivíduo a cometer uma infração legal. Nesta perspectiva, há uma correlação direta entre a percepção que o indivíduo tem da probabilidade de ser pego (ou punido) e sua propensão a cometer ilícitos. Quanto mais o cidadão acredita que sairá impune, mais ele sonega. Se acreditar que será punido, ele declara e paga os impostos devidos.

Os programas de cidadania lançam mão desta característica humana para estimular o comerciante a fazer o correto, emitindo documento fiscal e pagando seus impostos. Ao fazer com que inúmeros cidadãos peçam documentos fiscais e tenham motivação para fiscalizar se houve pagamento de impostos referentes àquela operação, o governo produz nos contribuintes de impostos uma percepção de aumento de risco de serem fiscalizados e punidos. Tal observação já surge em trabalhos como o de Allingham e Sandmo (1972, p. 2):

O contribuinte pode escolher entre duas estratégias: (1) Ele pode declarar sua renda real. (2) Ele pode declarar menos que a sua renda. Se ele escolher a segunda estratégia, seu retorno vai depender da possibilidade ou não de ser auditado pelas autoridades fiscais.

Este contribuinte faz ainda uma avaliação da análise econômica das vantagens de sonegar em contrapartida à opção de compliance (estar de acordo com as exigências de pagamento de imposto). Nesta análise, o fato de suas informações de cada operação estarem à disposição do governo faz com que o sonegador tenha a percepção de que sonegar e ter que pagar multas pode gerar custos mais altos que aqueles que ele teria estando adimplente com suas obrigações. Segundo Alm (1988, p. 8), "Diante da incerteza, indivíduos irão modificar a forma com que se comportam". O autor verifica o impacto no comportamento dos contribuintes com base em incertezas no comportamento do governo. Ainda segundo Alm (1988), políticas de impostos não previsíveis afetam virtualmente todo o conjunto de escolhas individuais: trabalhar, economizar, gastar, receber compensações e sonegar. Fica claro que todo um conjunto de comportamentos do indivíduo é dependente da conduta do governo.

O comportamento individual impacta o coletivo e vice versa. Em Unwillingness to Pay, Cowell e Gordon (1988) dizem que o indivíduo agora tem que levar em conta o efeito de sua própria decisão de sonegar sobre o montante de impostos recolhidos e a decisão de sonegar de outros contribuintes. O impacto generalizado de comportamentos individuais fatalmente conduz a uma análise destes mesmos impactos sobre o coletivo quando da implantação de programas de cidadania fiscal. Tais programas estimulam cidadãos a mudar de comportamento em seu dia a dia. Este conjunto de pessoas 
alterando seu comportamento fiscal gera uma repercussão significativa nos demais membros da sociedade.

Alm, Mcclelland e Schulze (1992) investigam as motivações para que as pessoas paguem impostos, considerando variáveis como punição, moral e transparência numa equação que define seu nível de tax compliance (decisão espontânea de cumprir corretamente as obrigações fiscais). São estas variáveis que produzem o estímulo para fazer com que os comerciantes e cidadãos cumpram seus papéis sociais no que diz respeito ao pagamento dos impostos.

Segundo Cowell e Gordon (1988) a introdução do conceito de bens públicos fecha a equação do modelo de taxa de evasão de impostos, ao levar em conta a influência que o propósito social dos impostos tem sobre a propensão individual a sonegar. Nesta análise, o contribuinte entende que, se os impostos estiverem sendo bem aplicados, fica mais difícil sonegar.

Numa lógica semelhante, Elster apud Mattos, Rocha e Toporcov (2013) conclui que os indivíduos pagam seus tributos na hipótese de considerarem que este é o padrão da sociedade na qual estão inseridos. Por isso mesmo, diferentes sociedades tem diferentes níveis de compliance. Em estudo de Mattos, Rocha e Toporcov (2013), são citadas diferenças entre os países no que diz respeito à underreporting (declarar menos que o real). No Chile empresas reportam mais de $98 \%$ das vendas, enquanto as firmas no Brasil reportam somente $67 \%$ das vendas. Este dado, visto na perspectiva contrária, ou seja, da parcela não reportada, dá a dimensão da diferença. Se, no Chile, $2 \%$ das vendas é omitido, no Brasil este percentual é estimado em 33\%, o que representa um volume 16,5 vezes maior.

Referência constante nos trabalhos de cidadania fiscal e compliance, Allingham e Sandmo (1972) criaram um modelo de análise da propensão a sonegar que é utilizado amplamente pelos demais estudiosos do tema. Em seu estudo, discorrem sobre a decisão tomada pelo contribuinte. "A decisão de declarar o imposto é uma decisão tomada em ambiente de incerteza. A razão para isto é que a decisão de não declarar um imposto que seria devido às autoridades fiscais não provoca automaticamente uma reação sob a forma de penalidade" (ALLINGHAM; SANDMO, 1972, p. 324). Ou seja, contribuinte pode tomar a decisão de declarar ou não sua atividade comercial, e frequentemente escolhe entre fazê-lo ou não baseando-se na premissa de que será flagrado e punido, ou, no sentido contrário, de que sua omissão será impune. Esta lógica é também intuitiva, pois parece óbvio que a chance de penalidade pelo ato ilícito seja fator para que um contribuinte pague seus impostos.

Sob uma ótica jurídica, o trabalho de Paschoal (2012) descreve a modulação de comportamento do indivíduo pelo Estado por meio das sanções positivas e negativas que atribuem responsabilidade ao cidadão e ao contribuinte:

\footnotetext{
Sem um processo de responsabilização, mesmo que informal e obscuro, não pode haver a aplicação de uma sanção, pois não existiria a comunicação, para o sujeito, de que aquela consequência está vinculada àquele determinado ato. Esse processo de responsabilização geralmente desenvolve-se por meio de um processo administrativo ou judicial (PASCHOAL 2012, p. 150).
}

Um programa de cidadania atribui aos personagens a responsabilidade pelos atos praticados por meio de sanções positivas, isto é, prêmios e devoluções em dinheiro e sanções negativas, quais sejam, multas pelo não cumprimento de obrigações como citado em Naritomi (2015).

A emissão de nota fiscal nas vendas de produtos e serviços é sempre obrigatória no Brasil, independentemente de programas de cidadania. A implementação jurídica de regras para estabelecer multas é atributo de cada ente federado. O uso destas sanções positivas e negativas faz parte do embasamento jurídico de todos os programas. No caso 
do Paraná, por exemplo, há o artigo 10 da Lei Estadual 18.451/2015:

Art. 10. Ficará sujeito à multa no montante equivalente a 10 UPF/PR (dez Unidades Padrão Fiscal do Estado do Paraná), por documento não emitido ou entregue, o fornecedor que deixar de emitir ou de entregar ao consumidor documento fiscal hábil, relativo ao fornecimento de mercadorias, bens ou serviços, sem prejuízo de outras penalidades previstas na legislação (PARANÁ, 2015).

Segundo Grabosky (1995, p. 257) a "dissuasão, baseada na ameaça de punições, é a estratégia fundacional do controle social dos países ocidentais". Já o crescimento das técnicas de encorajamento, segundo Bobbio (2007), surgiu com o advento do Estado social e regulador, em meados do século passado. Embora a punição seja um elemento sempre presente nas ações do Estado para determinar o comportamento dos cidadãos, os programas de estímulo à cidadania lançam mão, de maneira mais contundente, da estratégia do estímulo por meio da premiação a quem pede nota fiscal. O uso da sanção positiva, nas palavras de Paschoal (2012) tem sido tímido, mas usual ao longo do tempo:

No entanto, sanções premiais e estratégias regulatórias não punitivas sempre foram utilizadas pelo Estado para influenciar comportamentos, embora de forma mais tímida do que nos dias de hoje.

Os prêmios pagos àqueles que capturassem um fugitivo, os títulos e prêmios dados aos soldados que se destacavam nas guerras e aos cidadãos honrosos já estavam presentes nas regulações sociais da antiguidade (PASCHOAL, 2012, p.151).

Ainda, no trabalho de Paschoal (2012) detecta-se a análise dos dois focos de atuação regulatória do Estado em termos de estímulo e punição, quais sejam: deterrence (dissuasão) e compliance (conformidade):

O aumento do uso de estratégias alternativas às de comando e controle apoiadas em punição marca o que a literatura sobre o tema chama de passagem de um controle social baseado na dissuasão (deterrence) para um controle baseado na obediência legal (compliance). As estratégias estatais deixam de visar apenas dissuadir as pessoas a não cumprirem as regras e passam a estimulá-las a cumprirem (PASCHOAL 2012, p. 152).

Trabalhos mais recentes vão além do embasamento teórico que sustenta o estímulo à cidadania fiscal, seja por punição ou por estímulo. Estes trabalhos partem para a análise quantitativa de seus resultados. Santos (2015), conclui, em seu artigo, sobre a variação quantitativa de arrecadação do Estado de São Paulo:

O artigo mostrou que o Programa criou um impacto positivo e estatisticamente significativo sobre a arrecadação real do ICMS no estado de São Paulo da ordem de $\mathrm{R} \$ 600$ milhões, isso representa $12 \%$ (doze por cento) da média arrecadada pelo estado após a implantação da política até o mês de out./2014 (SANTOS, 2015, p. 12).

Neste aspecto, Santos (2015) afirma que houve um incremento significativo na arrecadação, enquanto que para Mattos, Rocha e Toporcov (2013) não é encontrada evidência significativa do programa nota fiscal paulista sobre a arrecadação total, mas apenas no setor terciário (varejo). Por isso, cabe a análise sobre as diferentes conclusões obtidas com base em métodos distintos.

Mattos, Rocha e Toporcov (2013) utilizam um modelo que considera a evolução temporal da arrecadação antes e depois da implantação dos programas de cidadania, tendo também a referência de Estados que não implantaram programas de cidadania: 


\author{
$y i t=\alpha i+\beta 0+\beta 1$ Tit $*$ Periodoit $+\beta 2$ Periodoit $+\beta 3 X i t+\delta t+" i t$ \\ Equação econométrica considerando períodos com e sem programas de cidadania em vários estados \\ brasileiros:(AC,AL,AM,AP,BA,CE,DF,GO,MA,MS,PA,PB,PI,RJ,RR,RS,SC,SE,SP,TO)
}

O modelo básico adotado pelo autor considera a variável ai, que captura o efeito fixo da unidade de observação, que é o Estado, e ot é uma dummy de tempo. Com a combinação destas variáveis, pode-se calcular a evolução da arrecadação de forma comparativa tanto entre estados distintos, como em tempos diferentes antes e depois da implantação de programas de cidadania. O detalhamento completo da metodolgia empregada e dos resultados obtidos se encontra em Mattos, Rocha e Toporcov (2013). Este estudo indica a prevalência de resultados positivos na arrecadação do varejo e impactos não significativos na arrecadação global de ICMS

O trabalho de Naritomi (2015) define a evolução de volume de vendas declarado e evolução de número de empregos como variáveis de aferição dos resultados do programa, numa ótica mais simples que a descrita por Mattos, Rocha e Toporcov (2013). As conclusões da autora levam a um resultado positivo da arrecadação de impostos em São Paulo em termos absolutos. Ainda nesta análise, são verificados os efeitos dos denunciantes; aquelas pessoas que, quando o contribuinte deixa de registrar uma operação de venda na qual ela teria direito a algum benefício, realizam denúncia ao órgão fiscalizador, expondo o contribunte à penalização por parte do Estado. Tal efeito é chamado de "Whistle Blowing" (soprar o apito), que significa alguém que realiza uma denúncia, e que assim é descrito nos estudos de Naritomi (2015):

\begin{abstract}
Juntos, o impacto de consumidores "soprando o apito" e o efeito heterogêneo de monitoramento por consumidores baseado na ameaça de sopro no apito é consistente com o argumento de que denunciantes podem ser parte significativa da explicação pela qual relatos de terceiras pessoas é tão efetivo para assegurar compliance (NARITOMI, 2015, p.22).
\end{abstract}

Os resultados obtidos pelas pesquisas, até o momento, no Brasil, apontam para indicadores gerais, agregando todos os segmentos de varejo. Mattos, Rocha e Toporcov (2013) relata em suas conclusões finais que:

É preciso levar em conta que a análise feita é bastante agregada. Análises desagregadas podem permitir uma melhor identificação do efeito da Nota Fiscal Paulista sobre setores específicos, mas infelizmente dados sobre arrecadação para cada um dos setores afetados pelo Programa (supermercados, farmácias, etc...) não estão disponíveis (MATTOS; ROCHA; TOPORCOV, 2013, p. 22).

\title{
3. Metodologia
}

Os diversos enfoques presentes nas pesquisas sobre programas de cidadania permitem uma visão abrangente do embasamento teórico que permeia os estudos na área. Para identificar os conceitos necessários para atingir o objetivo deste estudo, utilizaram-se as plataformas de pesquisa, a partir do Portal de Periódicos Capes que concede acesso a diversas bases de pesquisa acadêmica, além do Google Academics. Foram identificados os principais artigos para construir o arcabouço de referências que revelam o estado da arte para o estudo dos programas de cidadania. Por se tratar de assunto específico, utilizaram-se as palavras-chave em inglês: Increase on tax collection; Fiscal Citizenship Program; Fiscal Citizenship, Fiscal Programs para as buscas. Além destas, foram também utilizadas às palavras que dizem respeito ao nome dos programas, "nota paulista", "nota gaúcha" e "nota Paraná".

Para cada conjunto de termos, na base Scopus, foi aplicado o filtro do País Brasil, já que a pesquisa é para o território nacional. A Tabela 1 Sintetiza os resultados obtidos nas buscas realizadas nas bases supracitadas. 
Tabela 1: Resultados obtidos com os termos de pesquisa

\begin{tabular}{|c|c|c|}
\hline Termo de Pesquisa & Resultados & Relevantes para a pesquisa \\
\hline Increase on Tax Collection & 12 & 2 \\
\hline Fiscal Citzenship Programs & 3 & 3 \\
\hline Fiscal Citzenship & 6 & 4 \\
\hline Fiscal Programs & 48 & 4 \\
\hline Nota paulista & 21 & 3 \\
\hline Nota parana & 14 & 2 \\
\hline Nota gaúcha & 1 & 1 \\
\hline Total & 105 & 19 \\
\hline
\end{tabular}

Considerando-se as sobreposições dos resultados, com os diferentes termos, chegou-se ao portfólio bibliográfico final de artigos de 19 documentos que permitiram identificar as diferentes abordagens na elaboração dos programas de cidadania.

Em geral, os artigos pesquisados utilizam estudos do fenômeno da sonegação fiscal e suas motivações identificando as estratégias utilizadas no combate a sonegação e ao uso da participação da sociedade como redutor do estímulo à sonegação. Alm (1988), Cowell e Gordon (1988), assim como Schneider e Enste (2000), têm estudos relevantes sobre a influência destas estratégias. A evolução da Receita, tanto em termos absolutos como em termos relativos, foi também abordada nos estudos, oferecendo uma perspectiva quantitativa dos indicadores de impacto dos programas nos resultados de arrecadação de impostos dos estados e municípios que adotaram programas de cidadania.

Alguns estudos se detêm sobre o aumento de compliance por parte dos contribuintes. O conjunto de ações dos programas, inserindo o cidadão comum na equação da propensão a sonegar leva o contribuinte a alterar seu comportamento e elevar seu nível de compliance. A aderência a normas sociais de conduta, como citado por Elster (1989) apud Mattos, Rocha e Toporcov (2013) tende a ser elevada em face da publicidade como se vê em alguns trabalhos. Perspectivas

Pontualmente, são observadas outras dimensões de análise por parte dos pesquisadores. Vale ressaltar alguns estudos jurídicos comparando a base legal dos programas, bem como sua aderência a leis com a Responsabilidade Fiscal; o uso de tecnologias; o perfil de participantes por faixa etária ou categoria profissional além de vários outros aspectos que contribuem para um mosaico de percepções das transformações que tais programas trazem para a sociedade.

\section{Apresentação e análise dos resultados}

Cada um dos autores do portfólio bibliográfico desta pesquisa tem uma abordagem própria que reflete a ótica do pesquisador. O tema pode ser encarado numa perspectiva quantitativa, mensurando tão somente os impactos do programa, e, ainda assim, mostrar diferentes indicadores que evidenciam a evolução da arrecadação de impostos, número de documentos emitidos ou número de participantes. Há, ainda, a ótica jurídica da análise da fundamentação legal do programa e ainda a percepção qualitativa do programa.

Para melhor entender este universo de características estudadas, a Quadro 1 mostra os estudos selecionados, seus objetivos e a visão adotada pelos autores. 
Quadro 1: Estudos das abordagens dos autores

\begin{tabular}{cc}
\hline Autor (Ano): & Objetivo: \\
\hline Andrade et al. (2016) & $\begin{array}{c}\text { Verificar o comportamento de um grupo } \\
\text { de cidadãos representados pelos } \\
\text { acadêmicos do curso de Ciências } \\
\text { Contábeis da UEPG em relação ao } \\
\text { Programa de Estímulo à Cidadania } \\
\text { Fiscal }\end{array}$ \\
Carvalho et al; (2016) & $\begin{array}{c}\text { Descrever a formulação e } \\
\text { implementação do programa Nota } \\
\text { Fiscal Gaúcha }\end{array}$ \\
& $\begin{array}{c}\text { Identificar o grau de aderência das } \\
\text { dinâmicas instituídas pelo Programa } \\
\text { Carvalho et al. (2017) Fiscal Gaúcha aos elementos } \\
\text { fundantes da agenda para uma nova } \\
\text { governança pública. }\end{array}$
\end{tabular}

Dos Santos et. al (2014)

Santos et. al (2015)

Lima (2011)

Lins (2014)

Machado e Bioni (2016)

Moreira (2014)

Mrozinski (2014)

Naritomi (2015)
Abordar aspectos relacionados a todos os envolvidos no programa de cidadania fiscal como empresa, cidadão, contabilidade e Estado

Avaliar o impacto do Programa de Estímulo à Cidadania Fiscal do estado de São Paulo na a arrecadação real do ICMS

Avaliar a percepção dos cidadãos do programa Nota Legal

Verificar a existência de diferenças significativas de propensão à adoção de tecnologias, considerando os usuários e não usuário da nota legal.

Fazer um mapeamento das políticas de proteção dos dados pessoais nos programas de nota fiscal de 12 estados da federação

Analisar a natureza jurídica dos diversos benefícios atribuídos aos participantes dos programas estaduais de estímulo à emissão de nota fiscal

Estudar os benefícios para a educação do programa Nota Gaúcha

Estudar o Programa de Cidadania Nota Paulista
Comportamento do cidadão entre contadores

Aderência ao modelo de Gestão Social. Percepção de políticas públicas

Aderência ao modelo de Gestão Social. Percepção de políticas públicas

Mudanças comportamentais em face do programa de cidadania

Avaliar evolução da arrecadação de ICMS em termos absolutos

Percentuais de pessoas que usam e como avaliam o programa

Análise comparativa entre grupos de usuários e não usuários do programa em termos de uso de tecnologias

Verificação da confiabilidade do sigilo das informações coletadas nos programas

Embasamento jurídico dos programas e adequação à Lei de Responsabilidade Fiscal

Verificação de resultados para a educação

Verificação quantitativa dos resultados do Programa Nota Paulista 
Paschoal (2012)

Pereira (2014)

Ramos (2015)

Rodrigues (2015)

Silva (2012)

Toporcov (2009)

Mattos, Rocha e Toporcov (2013)

Vieira (2014)
Descrever e analisar o programa Nota

Fiscal Paulista, respondendo três principais questões: (i) Como funciona o programa Nota Fiscal Paulista? (ii)

Como o programa Nota Fiscal Paulista foi criado? (iii) Quais são as estratégias regulatórias que ele utiliza para atingir seus objetivos e como elas podem ser organizadas?

Explorar o comportamento de um grupo específico de cidadãos - os da Geração

Y (nascidos entre 1980 e 1999), em relação ao sistema do Programa de Incentivo à Cidadania Fiscal

Analisar o conjunto de Programas de cidadania implantados no Brasil

Avaliação dos impactos do Programa Sua Nota Vale Dinheiro na melhoria das atividades das instituições beneficiadas com o programa

Verificar se a Campanha Todos com a Nota Módulo Esportivo, instituída pelo Governo do Estado de Pernambuco, conscientiza ou não o cidadão acerca da importância social de sempre pedir a nota fiscal nas suas compras

Medir a eficiência dos Programas da Nota Fiscal Paulista e Alagoana, implantados pelos estados de São Paulo e Alagoas,

Avaliar o impacto do Programa Nota Fiscal Paulista sobre a arrecadação do Estado de São Paulo

Aplicação de técnicas de mineração em um programa de cidadania
Análise das estratégias de punição e recompensa como instrumentos do programa.
Comportamento de cidadão numa certa faixa etária.

Comparação entre vários programas de cidadania

Impacto nas entidades assistenciais beneficiadas pelo programa

Comportamento do cidadão. Avaliar se há conscientização da importância de pedir Nota Fiscal.

Mensuração de resultados do programa em arrecadação de impostos

Mensuração de resultados do programa em arrecadação de impostos

Indicadores de fidelidade das pessoas físicas participantes

Fonte: Autoria própria (2017).

O Portfólio bibliográfico abrange um conjunto de diferentes abordagens utilizadas pelos autores. Há uma tendência generalizada de mensurar o incremento da arrecadação de impostos. É importante relembrar que os programas de cidadania, como o nome diz, têm o objetivo de estimular a cidadania entre os participantes. A arrecadação é o efeito colateral, ainda que seja o resultado mais contundente e, por consequência, o mais estudado.

Os estudos quantitativos demonstram que houve evolução na arrecadação de impostos. Mattos, Rocha e Toporcov (2013) comparam a arrecadação total e no varejo. Já Naritomi (2015) verifica os resultados globais do Nota Paulista. Santos et. al (2015) também medem resultados dos programas enquanto Rodrigues (2015) mede especificamente os resultados para entidades assistenciais. Mrozinski (2014), por sua vez, avalia o resultado para escolas beneficiárias do programa gaúcho de cidadania. Fica claro, como citado por Mattos, Rocha e Toporcov (2013) que há uma lacuna do que diz 
respeito à análise quantitativa dos programas por segmento econômico, como farmacêutico, moveleiro, vestuário, etc.

$\mathrm{Na}$ perspectiva do direito, Moreira (2014) avalia o embasamento jurídico dos programas e adequação à Lei de Responsabilidade Fiscal, enquanto Carvalho et al. (2017) vão em busca dos elementos fundantes da agenda para uma nova governança pública. A inovação dos programas de cidadania apresenta um desafio para a adquação dos aspectos legais.

O enfoque em comportamento coletivo merece destaque no portfólio bibliográfico construído. Dos Santos (2014) fala de mudanças de comportamento de diferentes players, como contadores, cidadãos e empresários. Paschoal (2012) aborda as estratégias de punição e recompensa com seus impactos, enquanto Pereira (2014) enquadra sua análise comportamental na geração $Y$, jovens nascidos entre 1980 e 1999. Ramos (2015) dirige suas lentes aos acadêmicos de contabilidade e Silva (2012) avalia o grau de conscientização do cidadão mensurando a quantidade de pessoas que demosntram entendimento do papel de cidadania envolvido na solicitação de notas fiscais.

Outros aspectos, como a aderência ao modelo de Gestão Social, a avaliação que os contribuintes e participantes fazem dos programas, o uso de tecnologias, confiabilidade e sigilo das informações e comparações entre os diversos programas de cidadania em todas as dimensões avaliadas estão também no escopo dos estudos aqui elencados.

\section{Conclusão}

A revisão bibliográfica permitiu constatar que a abrangência do assunto é ampla e que as ações governamentais implementadas são convergentes em sua estratégia e escopo. Parte-se do estudo do comportamento dos cidadãos e dos comerciantes pagadores de impostos em vista a um programa de estímulo a atidudes com viés de cidadania. Tais programas fazem com que haja estímulo a solicitar documentos fiscais, o que gera a propensão a pagar impostos. Consequentemente, o impacto de ações de governo sobre o comportamento do indivíduo tem influência na cultura dos consumidores brasileiros.

A lógica subjacente aos diversos programas estudados é similar. Por meio do conhecimento do comportamento do indivíduo mediante perspectivas de benefícios individuais e/ou receio de punições, implantam-se regras que estimulam a emissão de notas fiscais e incremento do compliance por parte dos contribuintes.

Pode-se verificar que os estudos quantitativos demonstram a validade de tais programas como políticas de governo a estimular a correta declaração e pagamento dos impostos através de diferentes metodologias de quantificação de resultados. Outros estudos, entretanto, indicam que o crescimento da arrecadação não é homogeneamente significativo, como é o caso do trabalho de Mattos, Rocha e Toporcov (2013). Tal contexto reforça a relevância de estudos mais segmentados para clarear o impacto efetivo em distintos setores econômicos.

O conjunto de trabalhos científicos deste artigo permitiu a visão do estado da arte neste tema. Outros pesquisadores, interessados no aprofundamento destes assuntos, podem utilizar estas referências. A análise das metodologias que abordam o tema dos programas de cidadania em âmbito nacional mostrou que realmente o governo exerce influência sobre o comportamento dos cidadãos. O estímulo à participação do indivíduo, pedindo suas notas fiscais e recebendo benefícios, produz de fato, a participação da sociedade. Também, o aumento da possibilidade do contribuinte ser identificado em atividades de evasão fiscal contribui para um quadro mais equilibrado da arrecadação de impostos. Estes são, portanto, os aspectos a serem considerados pelos governos em futuras implantações de programas de cidadania. 
Nota-se que há uma oportunidade, ainda a não considerada nos estudos, quanto à identificação de como os programas impactam, de forma distinta, os vários segmentos econômicos afetos aos programas de cidadania no Brasil e/ou no mundo. Alguns setores pagam mais tributos e acabam estimulando mais o cidadão a participar dos programas de cidadania, enquanto que outros segmentos geram pouco ou nenhum retorno. Sugere-se, para pesquisas futuras, a separação dos ramos de atividade do comércio varejista, para que seja possível verificar se há mais impactos neste ou naquele segmento.

\section{Referências}

ALLINGHAM, M.; SANDMO, A. Income tax evasion: a theoretical analysis. Journal of Public Economics, v. 1, n. 3-4, p. 323-338, nov. 1972.

ALM, J. Uncertain tax policies, individual behavior, and welfare. The American Economic Review, v. 78, n. 1, mar. 1988. Disponível em: <http://www.jstor.org/stable/1814712>. Acesso em: 23 jun. 2017.

ALM, J.; MCCLELLAND G. H.; SCHULZE W. Why do People pay Taxes? Journal of Public Economics, v. 48, n. 1, june, 1992. Disponível em: <http://www.sciencedirect.com/science/article/pii/0047-2727(92)90040-M>. Acesso em: 21 jun. 2017.

ANDRADE, C. M. et al. O comportamento dos acadêmicos do curso de Ciências Contábeis da UEPG em relação ao Programa Nota Paraná. In: CONGRESSO EMPRESARIAL DE PRESTADORES DE SERVIÇO, 2016, Ponta Grossa. Anais... Ponta Grossa, CEPS, 2016.

BECKER, G. Crime and punishment: an economic approach. The Journal of Political Economy, v. 76, n. 2, p. 169-217, 1968. Disponível em: <http://www.journals.uchicago.edu/doi/pdfplus/10.1086/259394>. Acesso em: 24 jul. 2017.

COWELL F. A.; GORDON, J. Unwillingness to pay: tax evasion and public good provision. Journal of Public Economics, v. 36, n. 3, p. 305-321, aug. 1988.

CARVALHO, J. A. B. et al. O programa nota fiscal gaúcha: a cidadania fiscal como política pública. Revista Espacios, Caracas, v. 37, n. 28, p. 13, jun. 2016.

CARVALHO, J. A. B. et al. O Programa Nota fiscal gaúcha: tributação, capital social, controle popular e cidadania na prática. Revista Espacios, Caracas, v. 38, n. 4, p. 19, set. 2017.

DOS SANTOS, G. C. et al. Nota fiscal gaúcha: uma análise Técnica. Anais VIII Seminário de Iniciação Científica do Curso de Ciências Contábeis da FSG, Porto Alegre, v. 5, n. 1, p. 417-431, 2014.

GRABOSKY, P. N. Regulation by rewards: on the use of incentives as regulatory instruments. Law \& Policy, v. 17, n. 3, p. 257-282, july. 1995.

LIMA, A. L. P. Cidadania fiscal e o programa nota legal. 2011. 45 f. Monografia (Graduação em Direito) - Faculdade de Direito da Universidade de Brasília, Universidade de Brasília. Brasília. 
LINS, P. V. A propensão de usuários à adoção de tecnologias: um estudo com os usuários e não usuários do programa "Nota Fiscal" no Distrito Federal. 2014. 55 f. Monografia (Graduação) - Faculdade de Economia, Administração e Contabilidade, Universidade de Brasília. Brasília.

MACHADO, J.; BIONI, B. R. A proteção de dados pessoais nos programas de nota fiscal: um estudo de caso do "Nota Fiscal paulista". Liinc em Revista, Rio de Janeiro, v. 12, n. 2, p. 350-364, nov. 2016.

MAGALHÃES, A. M.; SIQUEIRA, L. Pernambuco's Fiscal Incentives Program: An Evaluation of Recent Performance. Latin American Business Review, v. 7, n 3-4, p. 151179, oct. 2008.

MOREIRA, C. T. C. Natureza jurídica dos incentivos decorrentes dos programas estaduais de estímulo à emissão de nota fiscal e sua aderência à Lei de Responsabilidade Fiscal. 2014. 120 f. Dissertação (Mestrado em Direito) - Programa de Pós-Graduação em Direito, Universidade Católica de Brasília, Brasília.

MROZINSKI, T. S. Financiamento, gestão e políticas de repasse de recursos na educação básica: um estudo da nota fiscal gaúcha. 2014. Monografia (Graduação) Faculdade de História, Universidade Federal da Fronteira Sul, Laranjeiras do Sul. 2014.

NARITOMI, J. Consumers as Tax Auditors. London School of Economics, Londres, 2015. Disponível em: http://www.med.uio.no/helsam/english/research/news-andevents/events/conferences/2015/vedlegg-warsaw/naritomi_enforcement april2015 2.pdf. Acesso em: 24 jul. 2017.

OLIVEIRA, S. A. M. Norberto Bobbio: Teoria política e direitos humanos. Revista de Filosofia, v. 19, n. 25, p. 361-372, jul./dez. 2007.

PARANÁ. Lei Estadual № 18.451 de 06 de abril de 2015. Criação do programa de estímulo à cidadania fiscal do estado do Paraná e adoção de outras providências. Diário oficial $n^{\circ}$ 9426, Curitiba, 07 abr. 2015. Disponível em: <http://www. notaparana.pr.gov.br/modules/conteudo/conteudo.php?conteudo=37>. Acesso em: 12 jul. 2017.

PASCHOAL, B. V. L. Punição, recompensa, persuasão e ajuda: estratégias regulatórias a partir do caso nota fiscal paulista. 2012. 212 f. Dissertação (Mestrado) Escola de Direito de São Paulo, Fundação Getúlio Vargas, São Paulo.

PEREIRA, A. N.; ANDRADE, V. V.; FARIA, A. C. Nota fiscal paulista: um estudo exploratório sobre o comportamento do cidadão da geração $Y$ na grande São Paulo. Revista Gestão e Políticas Públicas, São Paulo, v. 4, n. 2, p. 357-378, nov. 2014.

RAMOS, N. S. C. et al. Uma análise dos Programas de Incentivo a Cidadania Fiscal em Estados Brasileiros e Distrito Federal no Período de 2004 à 2012. Revista de informação contábil, Recife, v. 9, n. 2, p. 57-76, abr./jun. 2015.

RODRIGUES, D. S.; SOUSA, F. J. P. Avaliação dos impactos do Programa Sua Nota Vale Dinheiro na melhoria das atividades das instituições beneficiadas com 0 programa. 2015. 122 f. Dissertação (Mestrado em Políticas Públicas) - Programa de Pós- 
Graduação em Avaliação de Políticas Públicas, Universidade Federal do Ceará, Fortaleza.

SANTOS, P. F.; MENDONÇA, H. L. A.; CASSUCE, F.; RODRIGUES, C. O impacto do programa nota fiscal paulista na expansão das receitas tributárias do estado. Revista Espacios, Caracas, v. 36, n. 17, p. 3, jun. 2015.

SCHNEIDER F.; ENSTE, D. Shadow economies: size, causes and consequences. Journal of Econommic Literature, v. 28, p. 77-114, mar. 2000.

SILVA, R. M. A. Políticas públicas em cidadania fiscal: análise do comportamento do cidadão usuário do programa todos com a nota, do governo do estado de Pernambuco. 2012. 127 f. Dissertação (Mestrado em Administração Pública) - Escola Brasileira de Administração Pública e de Empresa, Fundação Getúlio Vargas, Rio de Janeiro.

TOPORCOV, P. Evidências empíricas do efeito da nota fiscal paulista e alagoana sobre a arrecadação estadual. 2009. 49 f. Dissertação (Mestrado em Economia) Escola de Economia de São Paulo, Fundação Getúlio Vargas, São Paulo.

MATTOS, E.; ROCHA, F.; TOPORCOV, P. Programas de incentivos fiscais são eficazes? Evidência a partir da avaliação do impacto do Programa Nota Fiscal Paulista sobre a arrecadação de ICMS. Revista Brasileira de Economia, Rio de Janeiro, v. 67, n. 1, p. 97-120, jan./mar. 2013.

VIEIRA, M. H. P. Aplicação de técnicas de mineração em um programa de concessão de benefícios ao consumidor: o caso do programa nota legal do distrito federal. 2014. 117 f. Dissertação (Mestrado em Profissional em Computação Aplicada) Programa de Pós-Graduação em Computação Aplicada, Universidade de Brasília, Brasília. 